\title{
Selective defunctionalization of citric acid to tricarballylic acid as a precursor for the production of high-value plasticizers
}

\author{
Wouter Stuyck, ${ }^{a}$ Jasper Verduyckt, ${ }^{a}$ Andraž Krajnc, ${ }^{b}$ Gregor Mali ${ }^{b}$ and Dirk E. De Vos *a \\ a. Centre for Membrane Separations, Adsorption, Catalysis and Spectroscopy for Sustainable Solutions (cMACS), KU Leuven, \\ Celestijnenlaan 200F, 3001 Leuven (Belgium). \\ b. National Institute of Chemistry, Hajdrihova 19, 1001 Ljubljana (Slovenia).
}

\begin{abstract}
Strong concerns about the toxicity and endocrine disrupting properties of widespread phthalate plasticizers stimulate the demand for safe and preferably biobased alternatives. Citric acid forms in this respect an excellent and abundant platform chemical for the production of valuable plasticizers. Here, we report a new and direct synthesis route for propane-1,2,3-tricarboxylic acid (PTA) from citric acid via a sequential one pot dehydration-hydrogenation process. This saturated triacid can serve as a basis for the production of tricarballylate esters via esterification, which have been shown to possess excellent plasticizing properties in vinyl resins. In the presence of a solid acid $\mathrm{H}$-Beta zeolite and $\mathrm{Pd} / \mathrm{C}$ hydrogenation catalyst, yields up to $85 \%$ of PTA were obtained under mild reaction conditions and in water as a green solvent. Partial dealumination of the $\mathrm{H}$-Beta zeolite by citric acid could be counteracted by reincorporating aluminium into the framework of the recycled $\mathrm{H}$-Beta zeolite through realumination, regenerating a significant fraction of the initial activity of the catalytic system. The success of the realumination procedure was verified via MAS NMR spectroscopy.
\end{abstract}

\section{Introduction}

With a production of 380 million metric tons (Mt) in $2015,{ }^{1}$ and a projected growth to $1124 \mathrm{Mt}$ by the year $2050,{ }^{2}$ it is clear that plastics are indispensable for our current and future modern society. On account of the increasing production and consumption of plastics, the production of plastic additives is forecasted to grow in a similar fashion. ${ }^{3}$ The largest market share of plastic additives is covered by plasticizers, ${ }^{4}$ which impart flexibility and processability to the resulting plastic product by lowering its glass transition temperature ${ }^{5}$ Over $90 \%$ of all plasticizers are used in PVC-formulations, with the majority of these plasticizers (65\%-70\%) consisting of ortho-phthalates. ${ }^{6}$ Growing concerns on these ortho-phthalates, due to their tendency to bioaccumulate and endocrine disrupting properties, ${ }^{7}$ have recently caused severe restrictions on these compounds. ${ }^{5}$ The generation of alternative plasticizers has mainly focussed on developing safe compounds that have a similar structure as these ortho-phthalates, including cyclohexanoates, trimellitates and terephthalates. ${ }^{5}$ However with increasing interest in renewable resources and low toxicity of plasticizers, bio-based plasticizers have recently gained much attention. In this respect, epoxidised (and acetylated) vegetable oils ${ }^{8}$ and isosorbide diesters ${ }^{9}$ have been shown to possess good plasticizing properties for PVC. In addition, effective plasticizers based on cinnamic acid, ${ }^{4}$ cardanol ${ }^{10}$ and 2,5-furandicarboxylic acid (FDCA $)^{11,12}$ have been developed as well. However, the limited availability of cinnamic acid and cardanol, the chemical modifications required for cardanol and the complexities in the synthesis of FDCA from hexoses, somewhat hamper the applicability of these renewable resources for plasticizer production.

Another class of biobased plasticizers consists of compounds that are based on citric acid. With its branched structure, three carboxylic functional groups and hydroxyl group, it may serve as a general basis to synthesize valuable plasticizers. Moreover, citric acid is a widely abundant renewable resource, since it can be produced via an efficient fermentation of biological waste, resulting in an annual production of 2.3 million tons in $2016 .{ }^{13}$ Citric acid itself is too polar to be compatible with PVC formulations. Therefore it is made more apolar via an esterification to for instance triethyl citrate (TEC) and tributyl citrate (TBC), often followed by an acetylation or butyrylation of the tertiary hydroxyl group to acetyl triethyl citrate (ATEC), acetyl tributyl citrate (ATBC) and butyryl trihexyl citrate (BTHC), respectively. When solely esterified, the resulting plasticizers still possess a prominent hydroxyl group, which makes them prone to migration out of the polymer matrix. ${ }^{14}$ After acetylation (ATBC) or butyrylation (BTHC), these plasticizers possess a quality that is comparable to the widely used di-2-ethylhexyl phthalate (DEHP). However, ATBC often remains more prone to leaching compared to DEHP. ${ }^{15,16}$ In addition, the derivatization of the tertiary hydroxyl group requires the use of anhydrides and strong Brønsted acid catalysts, ${ }^{17}$ thus involving harsh acidic conditions and stoichiometric acetic or butyric acid waste. Moreover, the use of petrochemically based anhydrides implicates a loss 
of the biobased aspect of the final plasticizer. An alternative approach is to remove this tertiary hydroxyl group of citric acid, prior to esterifying the resulting tricarballylic acid (propane-1,2,3-tricarboxylic acid, PTA) with the desired alcohol. The resulting tricarballylate plasticizers have shown excellent plasticizing efficiency in polyvinyl chloride (PVC) resins, with plasticizing properties such as tensile strength, modulus at $100 \%$, elongation at break and brittle point comparable to and in some cases even better than those of DEHP. ${ }^{18}$ Furthermore, these plasticizers also possess excellent light stability as well as a more satisfactory spew rating compared to abovementioned citrate plasticizers ${ }^{19}$ and can be expected to leach less from the polymer matrix due to their lower polarity. In addition to plasticizers for PVC, tricarballylates are also promising plasticizer candidates for polylactic acid, a biobased plastic that has gained much attention over the years. Due to the high density of aliphatic ester bonds of both, they are expected to be highly compatible with each other. ${ }^{20}$ However, a desirable direct route from the abundant citric acid to PTA has not yet been described. ${ }^{21}$ Recently, Verduyckt et al. optimised the route from citric acid towards methylsuccinic acid; PTA was observed in some cases as a side product with a maximal yield of $7 \% .^{22}$

Due to the large number of oxygen functionalities in biomass, deoxygenation routes have been a major topic of interest when considering these renewable resources for the production of valuable chemicals. ${ }^{23}$ To perform biomass dehydration under aqueous conditions, traditionally strong liquid Brønsted acids are applied. ${ }^{24-27}$ Concerning the low recyclability of these catalysts and the generation of large quantities of salt waste during product separation, heterogeneous acid catalysts have been proposed to replace strong liquid Brønsted acids. In this respect, zeolites have been proven to be active and stable under aqueous conditions ${ }^{28,29}$ and have shown good applicability for the cyclo-dehydration of alditols ${ }^{30-33}$ and the conversion of levulinic acid to methyltetrahydrofuran. ${ }^{34}$ In this work, we present the successful production of PTA via a sequential dehydration-hydrogenation of citric acid under mild conditions, in the presence of a solid acid $\mathrm{H}$-Beta zeolite and $\mathrm{Pd} / \mathrm{C}$ catalyst, water as a green solvent and $\mathrm{H}_{2}$ as a clean reductant. Furthermore we report on the stability and recyclability of the H-Beta zeolite catalyst.

\section{Experimental section}

\section{Materials}

All chemicals were used as received: citric acid monohydrate (Sigma-Aldrich, $\geq 99.5 \%$ ), tricarballylic acid (SigmaAldrich, $\geq 99 \%$ ), methylsuccinic acid (Sigma-Aldrich, 99\%), trans-aconitic acid (Sigma-Aldrich, 98\%), mesaconic acid (Sigma-Aldrich, 99\%), itaconic acid ( $\mathrm{TCl}, 99.0 \%)$, methacrylic acid (Acros Organics, 99.5\%), $\mathrm{HCl}\left(\mathrm{VWR}, 37 \%\right.$ in $\left.\mathrm{H}_{2} \mathrm{O}\right)$, $\mathrm{H}_{2} \mathrm{SO}_{4}$ (Acros, 95\% in $\mathrm{H}_{2} \mathrm{O}$ ), $\mathrm{Al}(\mathrm{OH})_{3}$ (Merck, >99.0\%), zirconium $n$-propoxide ( $\mathrm{TCl}$ Europe, 70 wt\% in $n$-propanol), isopropanol (Acros Organics, 99.5\%), zirconium(IV) acetylacetonate (abcr $\mathrm{GmbH}, 98 \%$ ) $\mathrm{H}_{2}$ (Air Liquide, N40), N2 (Air Liquide, $\alpha 1$ ), Pd/C (5 wt\%, Johnson Matthey), Amberlyst 15 hydrogen form wet (Sigma Aldrich), zeolite H-ZSM-5 (Zeolyst, CBV 3024E), zeolite H-MOR 6.8 (Norton), zeolite H-MCM-22 14 (China Catalyst Holding Co., Ltd.), zeolite HY 2.7 (China Catalyst Holding Co., Ltd.), zeolite H-Y 17.5 (China Catalyst Holding Co., Ltd.), zeolite H-Y 30 (Zeolyst, CBV 760), zeolite H-Beta 10.8 (PQ corporation, CP 811 BL-25), zeolite H-Beta 12.5 (Zeolyst, CP814e), zeolite H-Beta 32.5 (Zeocat, PB/65 H), zeolite H-Beta 75 (Clariant, HCZB 150), 2-methyltetrahydrofuran (Fischer Scientific, >99\%), maleic acid ( $\mathrm{TCl},>99 \%), \mathrm{D}_{2} \mathrm{O}$ (Sigma Aldrich, 99.9\% D).

\section{Catalytic reactions}

In a typical reaction, a glass vial $(5.5 \mathrm{~mL})$ was loaded with a solution of citric acid in deionized water $(2 \mathrm{~mL}, 0.1 \mathrm{M})$, a hydrogenation catalyst $(0.5 \mathrm{~mol} \% \mathrm{Pd} / \mathrm{C})$, an acid catalyst ( $\mathrm{H}$-Beta $10.8,0.1 \mathrm{~g})$ and a magnetic stirring bar. A teflon stopper was placed on the glass vial, partially closing it, after which it was placed in a stainless steel reactor (11 $\mathrm{mL}$ ). The reactor was subsequently sealed, purged five times with $\mathrm{N}_{2}$, purged three times with $\mathrm{H}_{2}$ and pressurized with 10 bar $\mathrm{H}_{2}$. Next, the reactor was placed in a heating block at $150{ }^{\circ} \mathrm{C}$ under continuous magnetic stirring at $750 \mathrm{rpm}$. After 20 hours the reactor was cooled in an ice bath to quench the reaction. The remaining gas was evacuated at room temperature and the solid catalysts were separated from the liquid reaction mixture by centrifugation. The reaction mixture was analysed with ${ }^{1} \mathrm{H}-\mathrm{NMR}$.

\section{Product analysis and identification}

To determine the product distribution and the amount of unreacted citric acid and citrate, the reaction mixtures were analysed by ${ }^{1} \mathrm{H}-\mathrm{NMR}$. For sample preparation, $300 \mu \mathrm{L}$ crude reaction mixture was mixed with $300 \mu \mathrm{L}$ of a 
solution of maleic acid in $\mathrm{D}_{2} \mathrm{O}(0.1 \mathrm{M})$ and transferred to an NMR tube. Maleic acid $(\delta=5.998 \mathrm{ppm}, \mathrm{s}, 2 \mathrm{H}) \mathrm{will}$ serve as an external standard for the quantification of the different compounds of the reaction mixture (ESI). ${ }^{1} \mathrm{H}-\mathrm{NMR}$ spectra were recorder on a Bruker Avance $400 \mathrm{MHz}$ spectrometer equipped with a sample case and a $5 \mathrm{~mm}$ PABBO BB/19F-1H/D probe with z-gradients and ATM accessory for Automatic Tuning and Matching. The broad singlet of the solvent water (around $\delta=4.65 \mathrm{ppm}$ ) was suppressed by applying a zgpr pulse program: p1 $9.75 \mu$ s; plw1 $15 \mathrm{~W}$; plw9 $5.710^{\wedge}(-0.5)$ W; ds 4; ns 32; d1 12 s; aq 2.55 s; sw 16 ppm; o1P on the resonance signal of water, automatically determined and selected. For correct quantitative analysis, the relaxation time (d1) of the pulse program was adjusted to $12 \mathrm{~s}$. Complete product identification by ${ }^{1} \mathrm{H}$ - and ${ }^{13} \mathrm{C}-\mathrm{NMR}$ can be retrieved from previous work of our group. ${ }^{22}$ To distinguish between the amount of citric acid and citrate, the crude reaction mixture $(200 \mu \mathrm{L})$ was acidified with a solution of $\mathrm{HCl}$ in water $(100 \mu \mathrm{L}, 2 \mathrm{M})$ prior to ${ }^{1} \mathrm{H}-\mathrm{NMR}$ analysis. Description of this method and interpretation of the ${ }^{1} \mathrm{H}-\mathrm{NMR}$ spectra are provided in the ESI.

The calculated conversions $(X)$ in this paper comprise the sum of the amount of citric acid and citrate that has reacted under the applied reaction conditions on a molar base. The distribution of the remaining substrate, citric acid and citrate, is also shown. The different selectivities (S) mentioned in this work are calculated as follows:

$$
\begin{gathered}
S_{P T A}=\frac{Y_{P T A}}{X} \\
S_{M S A}=\frac{Y_{M S A}}{X} \\
S_{\text {Fragmentation }}=\frac{Y_{\text {Acetic Acid }}+Y_{\text {Acetone }}}{X}
\end{gathered}
$$

Where PTA and MSA stand for propane-1,2,3-tricarboxylic acid and methylsuccinic acid respectively. Y represents the yield of the respective compounds, always on a molar base.

\section{Recycle experiments and zeolite realumination}

To recycle the catalyst, both solid catalysts were separated from the liquid fraction in the glass vial by means of centrifugation (4000 rpm, $10 \mathrm{~min}$ ). The liquid fraction is then removed, after which the solid catalysts were washed with water. This procedure is repeated three times. At last, the catalyst is dried overnight (16 hours) in a vacuum oven $\left(30^{\circ} \mathrm{C}, 30 \mathrm{mbar}\right)$. Both catalysts were reused directly in a new catalytic experiment, without further activation or regeneration steps. To calcine the $\mathrm{H}$-Beta zeolite prior to reuse, this catalyst first has to be separated from the hydrogenation catalyst $(\mathrm{Pd} / \mathrm{C})$ in the crude reaction mixture. This was achieved via an extraction, where the addition of 2-methyltetrahydrofuran to the crude reaction mixture resulted in a clear separation of both catalysts over both liquid phases: $\mathrm{H}$-Beta remains in the aqueous phase, while $\mathrm{Pd} / \mathrm{C}$ migrates to the organic phase. Next, the aqueous phase was transferred into a glass vial and $\mathrm{H}$-Beta was obtained after multiple washing and centrifugation steps, followed by overnight drying in a vacuum oven (cfr. supra) and calcination in a shallow bed in a porcelain crucible under static air $\left(550^{\circ} \mathrm{C}\right.$ for $\left.4 \mathrm{~h}, 2^{\circ} \mathrm{C} / \mathrm{min}\right)$.

Realumination of zeolite $\mathrm{H}$-Beta was achieved following a procedure recently published by Zhao et al. ${ }^{35}$ To obtain a sufficient amount of dealuminated $\mathrm{H}$-Beta zeolite to conduct the realumination, the two recycle experiments prior to the realumination procedure were performed on a larger scale in a $600 \mathrm{~mL}$ Parr reactor. For both recycle experiments, the $\mathrm{H}$-Beta catalyst to citric acid ratio was the same as under standard reaction conditions; For the first recycle experiment, the reactor was loaded with a solution of citric acid in deionized water $(200 \mathrm{~mL}, 0.1 \mathrm{M}), 0.5 \mathrm{~mol} \%$ $\mathrm{Pd} / \mathrm{C}$ and with $10 \mathrm{~g}$ of $\mathrm{H}$-Beta catalyst. For the second recycle experiment, the reactor was loaded with $160 \mathrm{~mL}$ of a $0.1 \mathrm{M}$ citric acid in deionized water solution, $0.5 \mathrm{~mol} \% \mathrm{Pd} / \mathrm{C}$ and $8 \mathrm{~g}$ of the recycled $\mathrm{H}$-Beta catalyst. Both recycle runs were conducted at $150{ }^{\circ} \mathrm{C}$ and with 10 bar $\mathrm{H}_{2}$ under continuous mechanical stirring (750 rpm). After each recycle run, the $\mathrm{H}$-Beta catalyst was recovered through liquid extraction, dried and calcined (cfr. supra). To realuminate the $\mathrm{H}$-Beta catalyst, $1 \mathrm{~g}$ of the twice dealuminated dry zeolite $\mathrm{H}$-Beta was mixed with an aqueous $\mathrm{Al}\left(\mathrm{NO}_{3}\right)_{3}$ solution $(20 \mathrm{~mL}, 0.1 \mathrm{M})$, after which the resulting mixture was sealed in a stainless steel autoclave. The autoclave was heated at $165^{\circ} \mathrm{C}$ for $72 \mathrm{~h}$. After quenching the autoclave, the material is obtained, washed and dried $\left(110{ }^{\circ} \mathrm{C}, 6 \mathrm{~h}\right)$ prior to calcination in a shallow bed in a porcelain crucible under static air $\left(550^{\circ} \mathrm{C}\right.$ for $\left.4 \mathrm{~h}, 2^{\circ} \mathrm{C} / \mathrm{min}\right)$. The resulting zeolite is named realuminated $\mathrm{H}$-Beta. 


\section{Solid-state NMR spectroscopy}

${ }^{27} \mathrm{Al},{ }^{29} \mathrm{Si}$ magic-angle spinning (MAS) and ${ }^{1} \mathrm{H}-{ }^{29} \mathrm{Si}$ cross-polarization (CP)MAS NMR experiments were carried out on a $600 \mathrm{MHz}$ Varian VNMRS spectrometer, equipped with a $3.2 \mathrm{~mm} \mathrm{HX} \mathrm{CPMAS} \mathrm{probe.} \mathrm{Larmor} \mathrm{frequencies} \mathrm{for}{ }^{27} \mathrm{Al}$ and ${ }^{29} \mathrm{Si}$ nuclei were $156.19 \mathrm{MHz}$ and $119.08 \mathrm{MHz}$, respectively. In all experiments, the sample rotation frequency was $20 \mathrm{kHz} .{ }^{27} \mathrm{Al}$ MAS NMR measurements employed a short $1.0 \mu$ s excitation pulse; 5000 scans were collected and the delay between the scans was $0.15 \mathrm{~s}$. In ${ }^{29} \mathrm{Si}$ MAS NMR measurements 90 -degree excitation pulse of $2.8 \mu \mathrm{s}$ and a repetition delay of $60 \mathrm{~s}$ were used; the number of scans was $500 .{ }^{1} \mathrm{H}-{ }^{29} \mathrm{Si}$ cross-polarization MAS (CPMAS) experiment used ramped-amplitude cross-polarization scheme with a duration of $5 \mathrm{~ms}$ and high-power proton decoupling; repetition delay was $3 \mathrm{~s}$ and the number of scans was 10000 . The applied formulas for the calculations of the total and framework $\mathrm{Si} / \mathrm{Al}$ ratios of all three zeolite samples can be retrieved from the ESI.

\section{Results and discussion}

\section{Sequential dehydration-hydrogenation of citric acid to PTA}

To obtain PTA from citric acid, a sequential dehydration-hydrogenation has to be performed (Scheme 1). First citric acid (1) is dehydrated to aconitic acid (2), after which this unsaturated compound has to be hydrogenated to obtain PTA (3). This first dehydration step is an equilibrium reaction and is enhanced by applying temperatures above $200{ }^{\circ} \mathrm{C} .{ }^{36}$ However, a high temperature also promotes the spontaneous decarboxylation reaction of aconitic acid (3) to itaconic acid (4), which can isomerise to mesaconic (5) and citraconic acid (6). ${ }^{36,37}$ Under reductive conditions these unsaturated diacids can be reduced to methylsuccinic acid (MSA) (7), ${ }^{22}$ or they can further decarboxylate to methacrylic (8) and crotonic acid (9), which in turn can be reduced to isobutyric (10) and butyric acid (11). ${ }^{22,37}$ Next to high temperatures, both decarboxylation steps can also be catalyzed by metals like $\mathrm{Ru}, \mathrm{Pt}$ or $\mathrm{Pd} .^{22,38}$

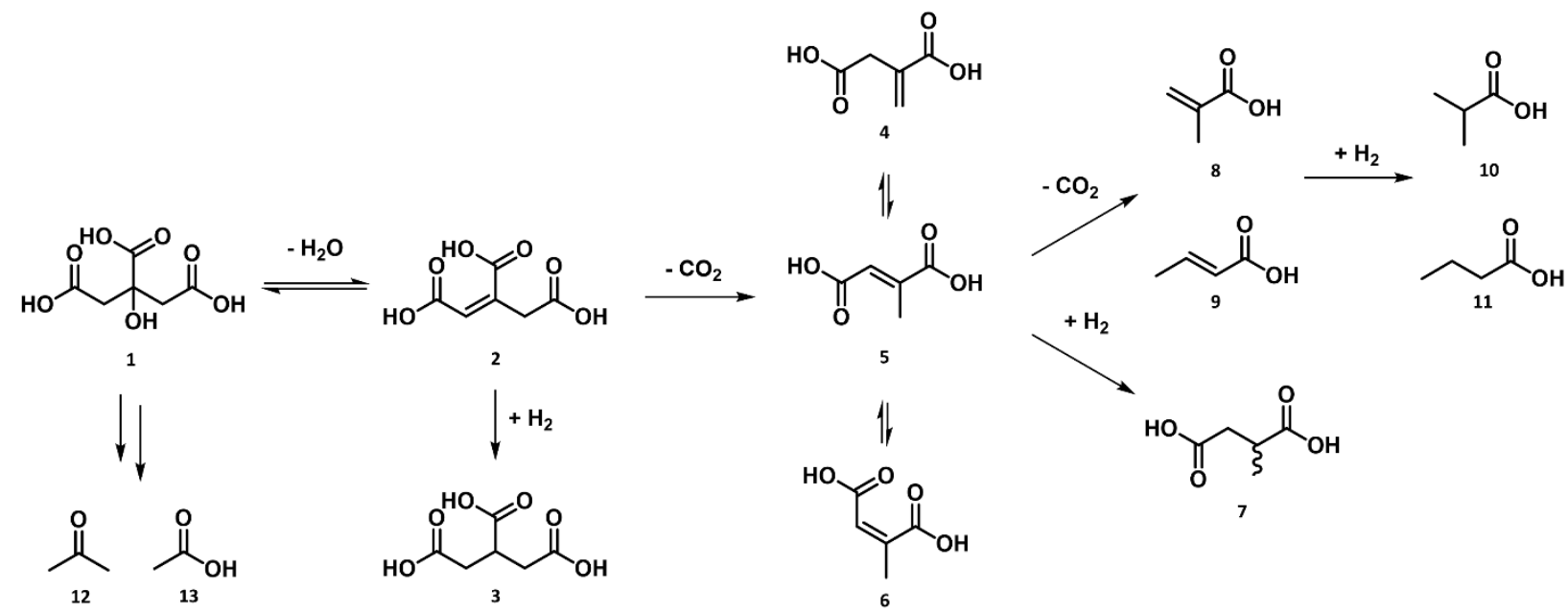

Scheme 1. Reaction scheme of the dehydration-hydrogenation of citric acid with undesirable decarboxylation side reactions.

For maximizing the yield of PTA (3) from citric acid (1), the decarboxylation of aconitic (2) to itaconic acid (4) is undesired, since it implies an irreversible loss of $\mathrm{CO}_{2}$. To suppress this spontaneous decarboxylation, citric acid was reacted at a low temperature of $140^{\circ} \mathrm{C}$, under reductive conditions in presence of $0.5 \mathrm{~mol} \% \mathrm{Pd}$ (Table 1 , entry 1 ). Even if good selectivities for PTA (3) were obtained (86\%), the conversion of citric acid remained low $(7 \%)$, since the dehydration to aconitic acid is slow at this temperature (2). Besides PTA and a small amount of MSA (7), a small fraction of fragmented products was observed. These consist of acetone (12) and acetic acid (13) and originate from radical fragmentation, which might be facilitated by non-reduced $\mathrm{Pd}$ species at the surface of the $\mathrm{Pd} / \mathrm{C}$ catalyst. ${ }^{22}$ Other side products like itaconic acid (4) (or its isomers mesaconic (5) and citraconic acid (6)) and products resulting from the second decarboxylation (8-11) were not observed in any of the experiments. Itaconic acid (4) is readily reduced to MSA (7) and is therefore less prone to a second decarboxylation under the applied low temperature reductive conditions. ${ }^{22,38}$ 
To promote the dehydration of citric acid (1) to aconitic acid (2), an acid catalyst was added in following experiments (Table 1, entries 2-11) under the same conditions as in entry 1 . To avoid harsh acidic conditions, limit salt waste and facilitate catalyst and product separation, an emphasis was made on heterogeneous solid acids. In this respect, Amberlyst-15, a strong acid sulphonated polystyrene (entry 2) and different zeolites in their protonated form (entries 3-12) were evaluated. In the case of Amberlyst-15, no improvement compared to the reaction without acid catalyst was noticed. In the presence of zeolite acid catalysts, a significant increase in activity was observed together with an increase in selectivity towards the desired product PTA (3) (except for entry 12). The product distribution shown in Table 1 comprises also citrate, besides citric acid. It was proven via ${ }^{27} \mathrm{AI}$ NMR and ICP-OES that part of the Al of the zeolites forms complexes with citric acid (cfr. infra). The 10-membered ring (MR) zeolites H-MCM-22 and H-ZSM-5 (entries 3 \& 4) were clearly outperformed by the $12 \mathrm{MR}$ zeolites $\mathrm{H}$-Mor (entry 5), $\mathrm{H}-\mathrm{Y}$ (entries 6-8) and $\mathrm{H}$-Beta (entries 9-12), indicating that the acid sites are more readily accessible in $12 \mathrm{MR}$ zeolites. The better activity of H-MCM-22 (2D pore system, entry 4) compared to H-ZSM-5 (3D pore system, entry 3), at a similar Si/Al ratio, can be assigned to the more accessible acid sites in the $12 \mathrm{MR}$ hemisupercages on the external surface of $\mathrm{H}-\mathrm{MCM}-22 .{ }^{39}$ Comparing $12 \mathrm{MR}$ zeolites, it is clear that H-Beta and $\mathrm{H}-\mathrm{Y}$ (3D pore system) are superior to H-Mor (2D pore system). For H-Y (entries 6-8) and H-Beta (entries 9-12), different Si/Al ratios were tested, where a higher Si/Al represents less but stronger Brønsted acid sites and more hydrophobic zeolite pores ${ }^{40,41}$ In both cases a lower Si/Al ratio resulted in a higher conversion, evidencing that the number of acid sites is more important than the strength of these Brønsted acid sites. This is illustrated by the proposed reaction mechanism in Scheme 2, where a higher amount of Al and thus Brønsted acid sites in the zeolite, will lead to more catalytic sites where the dehydration of citric acid (1) can take place. In contrast to previous research on the cyclodehydration of alditols in presence of zeolites, the hydrophobic effect of higher Si/Al zeolites does not seem to play a key role in the dehydration of citric acid (1) to aconitic acid (2). ${ }^{31-33}$

Table 1. Sequential dehydration - hydrogenation of citric acid. ${ }^{a}$

\begin{tabular}{|c|c|c|c|c|c|c|c|c|c|c|c|c|c|}
\hline & \multirow[b]{2}{*}{ Acid Cat. ${ }^{b}$} & \multirow[b]{2}{*}{$\mathrm{Si} / \mathrm{Al}$} & \multirow[b]{2}{*}{$\begin{array}{l}\text { Amount } \\
\text { cat. }^{c}[\mathrm{~g}]\end{array}$} & \multirow[b]{2}{*}{$\begin{array}{l}\mathrm{Pd} / \mathrm{C}^{d} \\
{[\mathrm{~mol} \%]}\end{array}$} & \multirow[b]{2}{*}{$\begin{array}{l}\text { Conc. }^{e} \\
{[\mathrm{M}]}\end{array}$} & \multirow[b]{2}{*}{$\begin{array}{l}\mathrm{P}_{\mathrm{H}_{2}} \\
\text { [bar] }\end{array}$} & \multirow[b]{2}{*}{$\mathrm{T}\left[{ }^{\circ} \mathrm{C}\right]$} & \multicolumn{2}{|c|}{ Distribution [\%] $]^{f}$} & \multirow[b]{2}{*}{$X[\%]^{h}$} & \multicolumn{3}{|c|}{ Selectivity [\%] } \\
\hline & & & & & & & & Citric acid & Citrate $^{g}$ & & PTA $^{i}$ & $\mathrm{MSA}^{j}$ & Fragm. ${ }^{k}$ \\
\hline 1 & - & - & - & 0.5 & 0.1 & 10 & 140 & 93 & 0 & 7 & 86 & 9 & $<1$ \\
\hline 2 & Amberlyst-15 & - & 0.02 & 0.5 & 0.1 & 10 & 140 & 93 & 0 & 7 & 75 & 21 & 4 \\
\hline 3 & H-ZSM-5 & 15 & 0.02 & 0.5 & 0.1 & 10 & 140 & 89 & 1 & 10 & 97 & 3 & $<1$ \\
\hline 4 & H-MCM-22 & 14 & 0.02 & 0.5 & 0.1 & 10 & 140 & 77 & 5 & 18 & 97 & 3 & $<1$ \\
\hline 5 & H-Mor & 6.8 & 0.02 & 0.5 & 0.1 & 10 & 140 & 72 & 5 & 24 & 88 & 9 & 3 \\
\hline 6 & $H-Y$ & 2.7 & 0.02 & 0.5 & 0.1 & 10 & 140 & 15 & 33 & 53 & 95 & 4 & 2 \\
\hline 7 & $\mathrm{H}-\mathrm{Y}$ & 17.5 & 0.02 & 0.5 & 0.1 & 10 & 140 & 54 & 12 & 34 & 93 & 5 & 2 \\
\hline 8 & $\mathrm{H}-\mathrm{Y}$ & 30 & 0.02 & 0.5 & 0.1 & 10 & 140 & 78 & 2 & 20 & 92 & 5 & 3 \\
\hline 9 & H-Beta & 10.8 & 0.02 & 0.5 & 0.1 & 10 & 140 & 71 & 1 & 28 & 96 & 1 & 2 \\
\hline 10 & H-Beta & 12.5 & 0.02 & 0.5 & 0.1 & 10 & 140 & 63 & 8 & 29 & 96 & 2 & 2 \\
\hline 11 & H-Beta & 32.5 & 0.02 & 0.5 & 0.1 & 10 & 140 & 86 & $<1$ & 14 & & 8 & 4 \\
\hline 12 & H-Beta & 75 & 0.02 & 0.5 & 0.1 & 10 & 140 & 92 & $<1$ & 8 & 85 & 11 & 4 \\
\hline 13 & $\mathrm{H}-\mathrm{Y}$ & 2.7 & 0.1 & 0.5 & 0.1 & 10 & 140 & 7 & 53 & 40 & 95 & $<1$ & 5 \\
\hline 14 & H-Beta & 10.8 & 0.1 & 0.5 & 0.1 & 10 & 140 & 33 & 20 & 47 & 97 & 1 & 1 \\
\hline 15 & H-Beta & 12.5 & 0.1 & 0.5 & 0.1 & 10 & 140 & 26 & 30 & 44 & 99 & 1 & $<1$ \\
\hline 16 & H-Beta & 10.8 & 0.1 & 3 & 0.1 & 10 & 140 & 36 & 22 & 42 & 85 & 14 & 1 \\
\hline 17 & H-Beta & 10.8 & 0.1 & 0.5 & 0.1 & 10 & 150 & 3 & 18 & 80 & 96 & 3 & $<1$ \\
\hline 18 & H-Beta & 10.8 & 0.1 & 0.5 & 0.1 & 10 & 160 & $<1$ & 5 & 95 & 90 & 9 & $<1$ \\
\hline 19 & H-Beta & 10.8 & 0.1 & 0.1 & 0.1 & 10 & 150 & 4 & 22 & 75 & 90 & 9 & 1 \\
\hline 20 & H-Beta & 10.8 & 0.1 & 0.5 & 0.1 & 6 & 150 & 8 & 21 & 71 & 94 & 6 & $<1$ \\
\hline 21 & $\mathrm{H}_{2} \mathrm{SO}_{4}$ & - & 2 eq.! & 0.5 & 0.1 & 10 & 150 & 88 & - & 15 & 94 & 2 & 4 \\
\hline 22 & $\mathrm{H}_{2} \mathrm{SO}_{4}$ & - & 8 eq. & 0.5 & 0.1 & 10 & 150 & 79 & - & 21 & 95 & 2 & 3 \\
\hline 23 & $\mathrm{SO}_{4}^{2-} / \mathrm{ZrO}_{2}$ & - & 0.1 & 0.5 & 0.1 & 10 & 150 & 71 & - & 29 & 68 & 24 & 8 \\
\hline
\end{tabular}




\begin{tabular}{|c|c|c|c|c|c|c|c|c|c|c|c|c|c|}
\hline 24 & $\mathrm{Al}(\mathrm{OH})_{3}$ & - & 0.5 eq. & 0.5 & 0.1 & 10 & 150 & 35 & 33 & 32 & 94 & 5 & $<1$ \\
\hline 25 & Zr-Beta & - & 0.1 & 0.5 & 0.1 & 10 & 150 & 94 & - & 6 & 95 & 1 & 3 \\
\hline 26 & H-Beta & 10.8 & 0.1 & 0.125 & 0.4 & 10 & 150 & 12 & 10 & 79 & 93 & 6 & $<1$ \\
\hline 27 & H-Beta & 10.8 & 0.1 & 0.063 & 0.8 & 10 & 150 & 30 & 6 & 65 & 92 & 7 & $<1$ \\
\hline
\end{tabular}

${ }^{a}$ Reaction conditions: water $(2 \mathrm{~mL}), 20 \mathrm{~h} .{ }^{b}$ Acid catalyst. ${ }^{c}$ Amount of acid catalyst. ${ }^{d}$ mol\% of Pd (5 wt.\% Pd/C) with respect to citric acid. ${ }^{e}$ Concentration of substrate citric acid. ${ }^{f}$ Distribution of the reactants, consisting of citric acid and Al-citrate, after reaction. The sum of both represents the total amount of unreacted substrate. ${ }^{g}$ The amount of citric acid that is present as Alcitrate determined by ${ }^{1} \mathrm{H}-\mathrm{NMR}$ after acidifying the mixture (See ESI). ${ }^{h}$ Conversion i.e. the amount of citric acid and citrate that has reacted. ${ }^{i}$ Propane-1,2,3-tricarboxylic acid. ${ }^{j}$ Methylsuccinic acid. ${ }^{k}$ Fragmentation products, which are represented by acetone and acetic acid. ' Equivalents with respect to citric acid.
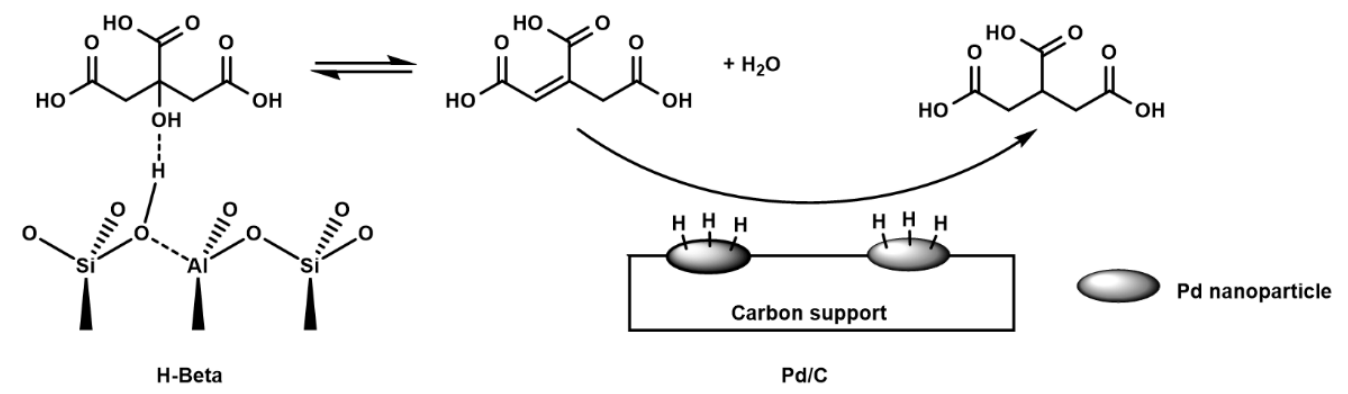

Scheme 2. Proposed reaction mechanism for the subsequent dehydration-hydrogenation of citric acid on $\mathrm{H}-\mathrm{Beta}$ and $\mathrm{Pd} / \mathrm{C}$ respectively.

Next, the amount of acid catalyst was varied for the three best performing catalysts: $\mathrm{H}-\mathrm{Y} 2.7, \mathrm{H}-\mathrm{Beta} 10.8$ and $\mathrm{H}$-Beta 12.5 (entries 13-15). An increase in the amount of both $\mathrm{H}$-Beta zeolites resulted in a higher conversion and selectivity for PTA (3), without further significant improvement above 5 wt\% (ESI, Table S2). Increasing the amount of $\mathrm{H}-\mathrm{Y} 2.7$ resulted in a significant decrease in conversion, although high selectivities for PTA (3) were maintained. This reduction can be assigned to the lower stability of aluminum-rich $\mathrm{H}-\mathrm{Y}$ in aqueous acidic conditions due to extensive dealumination, as suggested by the large amount of Al-citrate identified in the ${ }^{1} \mathrm{H}-\mathrm{NMR}$ spectra (entry 13). ${ }^{28,42-44}$ Increasing the amount of $\mathrm{Pd} / \mathrm{C}$ did not result in an increase in conversion and induced a reduction in selectivity towards PTA (3), presumably due to Pd-catalyzed decarboxylation of aconitic acid (2) to itaconic acid (4) (entry 16). ${ }^{22,38}$ The lack of rise in conversion with an increased amount of Pd also indicates that not the hydrogenation, but rather the dehydration reaction is the limiting step in the transformation of citric acid (1) to PTA (3). The highest yield of PTA (3) obtained thus far is $46 \%$ in presence of $0.1 \mathrm{~g} \mathrm{H}$-Beta 10.8 and $0.5 \mathrm{~mol} \% \mathrm{Pd}$ (entry 14); this catalyst combination was used to further optimize the reaction conditions.

Increasing the reaction temperature had a marked effect on the conversion of citric acid (1), reaching $80 \%$ at $150{ }^{\circ} \mathrm{C}$ (entry 17) and $95 \%$ at $160{ }^{\circ} \mathrm{C}$ (entry 18). Next to accelerating the dehydration of citric acid (1) to aconitic acid (2), an increase in reaction temperature also enhances the undesired decarboxylation of aconitic acid (2) to itaconic acid (4), as shown by the increased selectivity for MSA (7) at higher temperatures. However, selectivities of at least $90 \%$ for PTA (3) were obtained at both temperatures. To further investigate the conversion of citric acid and product formation at these elevated temperatures, time profiles were recorded at $150^{\circ} \mathrm{C}$ and $160{ }^{\circ} \mathrm{C}$ (Figure 1). Both profiles have a similar shape; after $10 \mathrm{~h}$ at $160^{\circ} \mathrm{C}$ a similar PTA yield (79\%) was observed as after $20 \mathrm{~h}$ at $150{ }^{\circ} \mathrm{C}(77 \%)$. From the profile at $150^{\circ} \mathrm{C}$ it is also clear that Al citrate is formed almost instantaneously and that its concentration remains approximately constant over time. Thus, even if partial dealumination of $\mathrm{H}$-Beta 10.8 has already taken place at the onset of the reaction, the catalytic system remains active, indicated by the linear increase in PTA (3) production over time. From the profile at $150{ }^{\circ} \mathrm{C}$ it also seems that Al citrate might be a dead end product, since its concentration remains more or less unaffected over time. However, when the reaction temperature is raised to $160{ }^{\circ} \mathrm{C}, \mathrm{Al}$ citrate is converted as well but only after most of the citric acid (1) is converted. This indicates that Al citrate is less reactive than citric acid (1) but not a dead end product. 

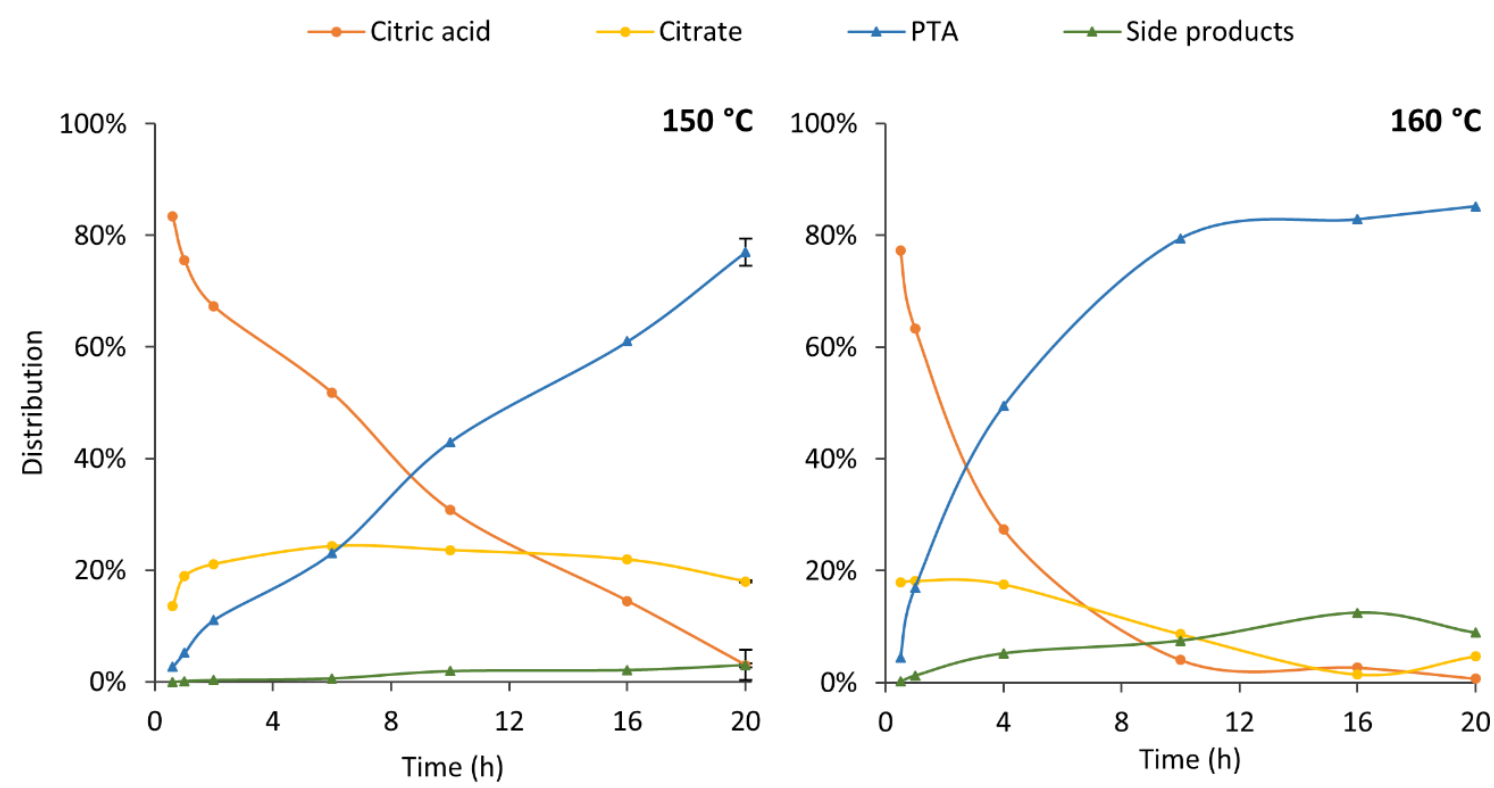

Figure 1. Time profiles of the sequential dehydration-hydrogenation of citric acid at $150{ }^{\circ} \mathrm{C}$ (left) and $160^{\circ} \mathrm{C}$ (right). Each series of data points at a specific time corresponds to a different batch reaction. The error bars at $150{ }^{\circ} \mathrm{C}$ and $20 \mathrm{~h}$ represent the standard deviation with a sample size of $\mathrm{n}=4$. Reaction conditions: Citric acid $(0.2 \mathrm{mmol})$, water $(2 \mathrm{~mL}), 0.1 \mathrm{~g} \mathrm{H}-\mathrm{Beta} 10.8,0.5 \mathrm{~mol} \% \mathrm{Pd}$ (5 wt\% Pd/C), 10 bar $\mathrm{H}_{2}$. Legend: Citric acid (orange), Citrate (yellow), PTA (blue), Side products* (green). * Side products consist of MSA and less than $1 \%$ of fragmented products in all cases.

Both lowering the amount of $\mathrm{Pd} / \mathrm{C}$ (entry 19 ) and $\mathrm{H}_{2}$-pressure (entry 20) resulted in a slightly lower conversion of citric acid (1) and lower selectivity towards PTA (3). This indicates that a sufficient, but still industrially relevant amount of $\mathrm{Pd} / \mathrm{C}$ and $\mathrm{H}_{2}$-pressure are required to direct the unsaturated aconitic acid (2) to the desired hydrogenated product PTA (3) and avoid decarboxylation to itaconic acid (4). Further variations of both parameters are included in Table S3 and Table S4 in the ESI.

Homogeneous Brønsted acid catalysts were ineffective to catalyze the dehydration of citric acid (1) (entries 21 \& 22); a conversion of only $21 \%$ was reached in presence of 8 eq. $\mathrm{H}_{2} \mathrm{SO}_{4}$. The superiority of $\mathrm{H}$-Beta 10.8 compared to $\mathrm{H}_{2} \mathrm{SO}_{4}$ might be ascribed to the stronger acidity of the Brønsted acid sites in the zeolite. However, when a solid superacid $\left(\mathrm{SO}_{4}{ }^{2-} / \mathrm{ZrO}_{2}\right)$ was applied under the same conditions (entry 23$)$, again a low conversion and in this case also a lower selectivity for PTA (3) were observed. From these results, it can be concluded that catalysts with predominantly strong Brønsted acidity are not effective, which could already be perceived from the performance of Amberlyst 15 (entry 2). To further investigate the role of the acid catalyst, 0.5 eq. of $\mathrm{Al}(\mathrm{OH})_{3}$ was applied as a homogeneous Lewis acid catalyst (entry 24). Although large amounts of Al citrate were observed, a conversion of $35 \%$ was reached and high selectivities were obtained, indicating that Lewis acids can also facilitate the dehydration of citric acid (1) in acidic aqueous media. Applying a Lewis acid Zr-Beta zeolite on the other hand, did not result in an effective conversion of citric acid (1) (entry 25).

These findings suggest that next to its hydrothermal stability and adequate amount and accessibility of acid sites, zeolite H-Beta 10.8 has another particular feature that makes it more suitable than other homogeneous and heterogeneous acids for the dehydration of citric acid (1). Next to strong Brønsted acidity, H-Beta also possesses Lewis acidity which can originate both from octahedrally coordinated extra-framework Al-species as well as from "perturbed" tetrahedrally coordinated framework Al-species. ${ }^{45-47}$ The latter are generated on hydrolysed tricoordinated $\mathrm{Al}$ species $\left(\mathrm{Al}(\mathrm{SiO})_{3} \mathrm{OH}\right)$ which under the applied aqueous conditions of this work will be predominantly present in (pseudo)-octahedral symmetry. ${ }^{46-50}$ Considering the significant amount of Al citrate formation during the catalytic reactions in presence of $\mathrm{H}$-Beta and the decrease of activity upon its recycling (cfr. infra), it is clear that a notable amount of Al will be leached from the zeolite. During this dealumination process, octahedrally coordinated (framework or extra-framework) Al species are formed (Lewis acids) at the expense of tetrahedrally coordinated Al species, which are associated with Brønsted acid sites. It therefore seems that when a 
citric acid (1) molecule is coordinated to such a Lewis acid, it is more prone to dehydration when it encounters a strong Brønsted acid site in its close vicinity. Since about half of the Al sites of low Si/Al Beta zeolites $(10<\mathrm{Si} / \mathrm{Al}<18)$ are present as Al pairs, of which at least $50 \%$ face the same zeolite channel, combined presence of Lewis and Brønsted acid sites is highly likely to occur in zeolite H-Beta channels. ${ }^{49,51}$ Here we propose that this combined interaction, together with previously cited characteristics of $\mathrm{H}$-Beta 10.8 , accounts for the superiority of this solid acid for the dehydration of citric acid (1) to aconitic acid (2).

A final set of experiments included the increase of the citric acid concentration (entries 26 \& 27), to mimic a more industrially relevant aqueous citric acid stream. For both experiments the amount of both catalysts was kept constant (0.1 g H-Beta 10.8 and $2.1 \mathrm{mg} \mathrm{Pd} / \mathrm{C}$ ), resulting in a decrease of the catalyst/substrate ratio at higher concentrations of citric acid. At these elevated concentrations of citric acid, the acidity of the aqueous medium increases, which will facilitate the dehydration reaction as well. Starting from $0.8 \mathrm{M}$ citric acid (1), an acceptable conversion of $65 \%$ and high selectivities for PTA (3) of $92 \%$ were obtained, ensuring the industrial relevance of this catalytic system.

\section{Recyclability, dealumination and realumination of zeolite H-Beta 10.8}

The observation of significant quantities of Al citrate in the reaction mixtures with zeolite catalysts, suggests an inevitable loss of Al through dealumination. To investigate whether this dealumination affects the stability and activity of the catalyst, recycling tests were performed (Figure 2 \& Table S5 ESI). Directly reusing the catalytic system (both $\mathrm{H}$-Beta and $\mathrm{Pd} / \mathrm{C}$ ) in consecutive recycle runs resulted in a significant decrease of the activity of $\mathrm{H}$-Beta, as evidenced by the decrease in citric acid (1) conversion ( $80 \%$ to $45 \%$ ) and PTA (3) yield (77\% to $42 \%)$. This gradual decay in activity can be attributed to loss of acid sites due to dealumination. This is illustrated by the formation of additional citrate in the first and second reuse experiments (Figure 2 \& Table 5 ESI). When zeolite H-Beta was separated from $\mathrm{Pd} / \mathrm{C}$ through a liquid extraction with 2-methyltetrahydrofuran (Me-THF) and calcined at $550{ }^{\circ} \mathrm{C}$ prior to the following catalytic run, the decreases in citric acid (1) conversion (80\% to 55\%) and PTA (3) yield (77\% to 53\%) were less pronounced and high selectivities for PTA (3) remained (> 95\%) for both recycle runs. A possible explanation for this increase in citric acid (1) conversion and PTA (3) yield compared to directly reusing both catalysts, is that some of the (partially) hydrolysed octahedral framework and extraframework aluminum is reverted to tetrahedral framework aluminum upon calcination of $\mathrm{H}$-Beta, thereby delaying the dealumination in the subsequent recycling experiment.

In an endeavour to restore the activity of the zeolite catalyst, a twice reused and calcined $\mathrm{H}$-Beta (further denominated as dealuminated $\mathrm{H}$-Beta) was realuminated with $\mathrm{Al}\left(\mathrm{NO}_{3}\right)_{3}$ following a recently published procedure of Zhao et al. ${ }^{35}$ Applying this realuminated $\mathrm{H}$-Beta catalyst under the same reaction conditions resulted in a clear increase in citric acid conversion (72\%) and PTA yield (68\%). Although the high selectivity of PTA is again maintained (>95\%), the activity of the fresh $\mathrm{H}$-Beta 10.8 catalyst could not be fully restored. To monitor the crystallinity of the different zeolite samples, X-ray diffractograms of the fresh, dealuminated and realuminated $\mathrm{H}$-Beta catalyst were acquired (Figure S5 ESI). The XRD diffractogram of the fresh $\mathrm{H}$-Beta 10.8 shows diffraction peaks characteristic for zeolite Beta framework structure at $2 \theta$ of $7.6^{\circ}, 13.5^{\circ}, 14.4^{\circ}, 21.3^{\circ}$ and $22.5^{\circ}$. For the dealuminated $\mathrm{H}$-Beta sample, a decrease in peak intensities is noticed, evidencing some loss of crystallinity. Upon realumination, the loss of crystallinity is rather limited. 


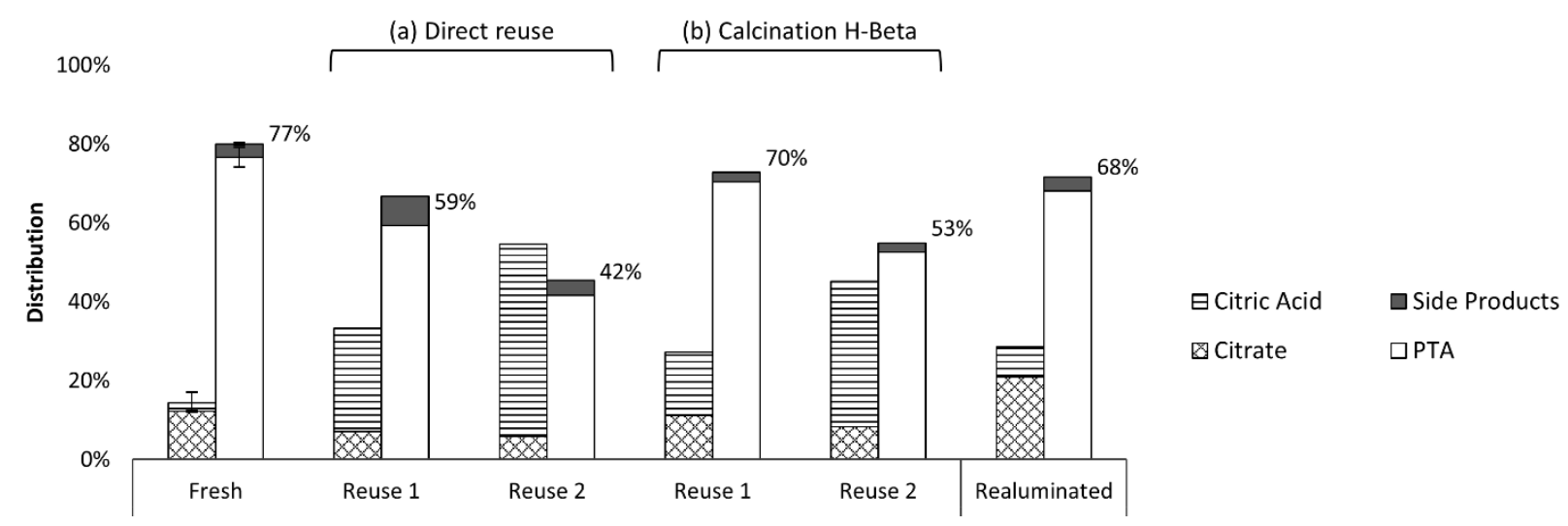

Figure 2. Recycling of the catalytic system. (a) Direct reuse, without calcination of $\mathrm{H}$-Beta. (b) $\mathrm{H}$-Beta is calcined at $550{ }^{\circ} \mathrm{C}$ prior to reuse. Reaction conditions: $0.1 \mathrm{~g} \mathrm{H}-B e t a, 0.5 \mathrm{~mol} \% \mathrm{Pd} / \mathrm{C}$, citric acid $0.2 \mathrm{mmol}$, water $2 \mathrm{~mL}, 10 \mathrm{bar} \mathrm{H}_{2}, 150^{\circ} \mathrm{C}, 20 \mathrm{~h}$. Legend: Citrate (diamond), citric acid (horizontal lines), PTA (white), side products* (dark). The percentages denote the yield of PTA. The error bars for the fresh $\mathrm{H}$-Beta catalyst represent the standard deviation with a sample size of $n=4$. ${ }^{*}$ Side products consist of MSA and less than $1 \%$ of fragmented products in all cases.

Since XRD gives no detailed local insight, solid state NMR was invoked to study the loss and reincorporation of Al upon dealumination and realumination respectively in more detail. ${ }^{29} \mathrm{Si}$ MAS NMR spectra (Figure 3 ) and ${ }^{27} \mathrm{Al}$ MAS NMR spectra (Figure 4) were recorded for the fresh H-Beta 10.8, for the dealuminated H-Beta, and for the realuminated $\mathrm{H}$-Beta catalysts. To reliably assign the resonance lines of the ${ }^{29} \mathrm{Si}$ MAS NMR spectra, ${ }^{1} \mathrm{H}-{ }^{29} \mathrm{Si}$ CPMAS NMR spectra were recorded as well (ESI). The NMR spectra were normalized indirectly in such a way that the total integrals of the ${ }^{29} \mathrm{Si}$ MAS NMR spectra of the three zeolites were equal. This approach is reasonable, since it can be assumed that the silicon content in the samples changes very little during de- and realumination. After this normalization, ${ }^{27} \mathrm{Al}$ MAS NMR spectra offer a solid quantitative comparison of the total amount of Al within the samples and of the ratio of framework and extra-framework Al species (Figure 4). The framework- and total Si/Al ratio of the three zeolite samples can be estimated from deconvolution and integration of the ${ }^{29} \mathrm{Si}$ MAS NMR and ${ }^{27} \mathrm{Al}$ MAS NMR spectra whilst taking into account the amount of extra-framework Al from ${ }^{27} \mathrm{Al}$ MAS NMR spectra for the calculations of the total $\mathrm{Si} / \mathrm{Al}$ (Table 2; calculations can be found in ESI). After two consecutive catalytic runs, the framework Si/Al of the H-Beta zeolite increased from 11.4 to 39.5, indicating significant loss of Al from the zeolite framework through dealumination. Through realumination, the framework Si/Al decreases again to 17.7, illustrating that $\mathrm{Al}$ is reincorporated into the zeolite framework. However, the initial framework Si/Al could not be fully restored.

Table 2. Normalized Al-distribution from ${ }^{27} \mathrm{Al}$ MAS NMR spectra and estimated framework- and total Si/Al ratio

\begin{tabular}{|c|c|c|c|c|}
\hline Zeolite catalyst & Al Norm-Fr & Al Norm-EF & $\mathrm{Si} / \mathrm{Al} \mathrm{lr}_{\mathrm{r}}$ & $\mathrm{Si} / \mathrm{Al}_{\text {Tot }}$ \\
\hline Fresh H-Beta 10.8 & 94.0 & 6.0 & 11.4 & 10.8 \\
\hline Dealuminated H-Beta & 27.1 & 0.4 & 39.5 & 38.9 \\
\hline Realuminated H-Beta & 60.6 & 4.9 & 17.7 & 16.4 \\
\hline
\end{tabular}

The chemical shifts that are observed in the ${ }^{27} \mathrm{Al}$ MAS NMR spectra are in agreement with previously reported chemical shifts for H-Beta zeolites. ${ }^{52-56}$ The peaks in the region between -30 and 10 ppm are assigned to extraframework and framework octahedral aluminum. For the fresh $\mathrm{H}$-Beta 10.8, these peaks correspond to a superposition of a sharp signal at around $0 \mathrm{ppm}$ and a broad peak of aluminum that experiences a large quadrupolar interaction. The former corresponds to aluminum species in highly symmetrical environment similar to $\mathrm{Al}\left(\mathrm{H}_{2} \mathrm{O}\right)_{6}{ }^{3+}$, while the latter is assigned to a more hydrolyzed, distorted framework octahedral Al species. ${ }^{53-56}$ This distorted octahedral framework aluminum is attached more loosely to the zeolite structure ${ }^{56}$ and is thus more accessible for citric acid, resulting in a significant decrease of this octahedral Al species in the dealuminated zeolite (Figure 4). A small amount of $\mathrm{Al}\left(\mathrm{H}_{2} \mathrm{O}\right)_{6}{ }^{3+}$ octahedral species remains present in the dealuminated zeolite due to continuous hydrolysis of tetrahedral framework Al under the applied aqueous citric acid conditions. The resonance between 50 and $65 \mathrm{ppm}$ is typical of tetrahedral framework Al. For the fresh zeolite H-Beta 10.8, this resonance consists of a superposition of two contributions: one peak at $54 \mathrm{ppm}$, which corresponds to aluminum atoms on T1 and T2 sites 
in the H-Beta framework, and one peak at 57 ppm which can be assigned to aluminum atoms on T3-T9 sites. ${ }^{53,54}$ Under the applied reaction conditions, Al seems to be preferentially removed from these T3-T9 sites since the contribution of the peak at $57 \mathrm{ppm}$ is severely lowered for the dealuminated sample, while the peak at 54 ppm remains more preserved (Figure 4). The increased resistance towards dealumination of framework Al on T1 and T2 positions is in agreement with previously reported dealumination of zeolite $\mathrm{H}$-Beta under steaming conditions ${ }^{53,54}$ and acid leaching. ${ }^{57,58}$

During realumination, most of the aluminum is reincorporated into the zeolite $\mathrm{H}$-Beta framework, as indicated by a larger increase of the contribution of Al to the resonance of framework Al compared to the resonance of extraframework Al. Nonetheless, the distribution of Al over the different framework T sites after realumination does not resemble the distribution that was observed in the original sample. This is also reflected in the ${ }^{29} \mathrm{Si}$ MAS NMR spectra, where the contributions of the $\mathrm{Si}(\mathrm{OSi})_{3}(\mathrm{OAI})$ and $\mathrm{Si}(\mathrm{OSi})_{2}(\mathrm{OAI})_{2}$ peaks are significantly different in the fresh and realuminated zeolite (Figure 3 ). Realumination also changes the shapes (and widths) of the signals that belong to tetrahedrally coordinated $\mathrm{Al}$; the resonance of the realuminated sample is not as sharp as the resonance of the original sample. These findings suggest that during realumination Al does not incorporate integrally into the sites from which it was removed during the dealumination process. A possible explanation for this dissimilarity can be found in the recycling procedure of the zeolite catalysts, where a calcination at $550{ }^{\circ} \mathrm{C}$ is performed between two recycle runs. This calcination might have induced a loss of the silanol nests that were originally generated by removal of Al during the sequential dehydration-hydrogenation of citric acid, resulting in an irreversible change of the zeolite structure. However, upon realumination a considerable amount of the catalytic activity was restored (Figure 2), illustrating that this realumination technique is a suitable approach to recycle the applied zeolite $\mathrm{H}$-Beta catalyst and in general the whole catalytic system.

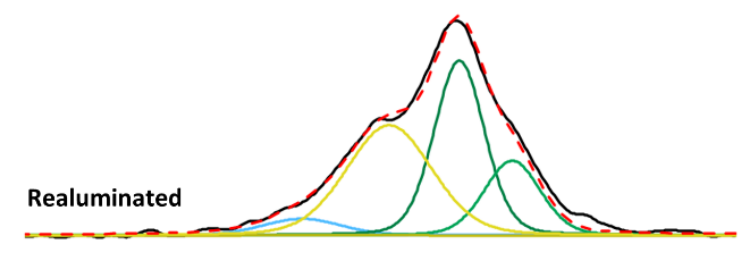

\begin{tabular}{lcc} 
& Chemical shift $(p p m)$ & Fraction (\%) \\
\hline $\mathrm{Si}(\mathrm{OSi})_{2}(\mathrm{OH})_{2}$ & $-92,7$ & 0,2 \\
$\mathrm{Si}(\mathrm{OSi})_{3}(\mathrm{OH})$ & $-99,5$ & 5,5 \\
$\mathrm{Si}(\mathrm{OSi})_{4-n}(\mathrm{OAI})_{n} \quad(n=1,2)$ & $-101,9$ & 0,0 \\
$\mathrm{Si}(\mathrm{OSi})_{4-n}(\mathrm{OAl})_{n} \quad(n=1)$ & $-105,6$ & 39,7 \\
$\mathrm{Si}(\mathrm{OSi})_{4}$ & $-110,6$ & 37,0 \\
$\left.\mathrm{Si}_{(\mathrm{OSi}}\right)_{4}$ & $-114,3$ & 17,6
\end{tabular}

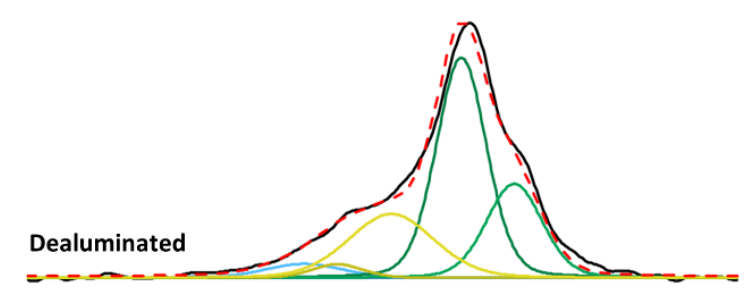

\begin{tabular}{lcc} 
& Chemical shift $(p p m)$ & Fraction (\%) \\
\hline $\mathrm{Si}(\mathrm{OSi})_{2}(\mathrm{OH})_{2}$ & $-92,7$ & 0,4 \\
$\mathrm{Si}(\mathrm{OSi})_{3}(\mathrm{OH})$ & $-99,5$ & 4,6 \\
$\mathrm{Si}(\mathrm{OSi})_{4-n}(\mathrm{OAl})_{n} \quad(n=1,2)$ & $-101,9$ & 3,0 \\
$\mathrm{Si}(\mathrm{OSi})_{4-n}(\mathrm{OAI})_{n} \quad(n=1)$ & $-105,6$ & 23,1 \\
$\mathrm{Si}(\mathrm{OSi})_{4}$ & $-110,6$ & 46,7 \\
$\mathrm{Si}(\mathrm{OSi})_{4}$ & $-114,3$ & 22,2
\end{tabular}

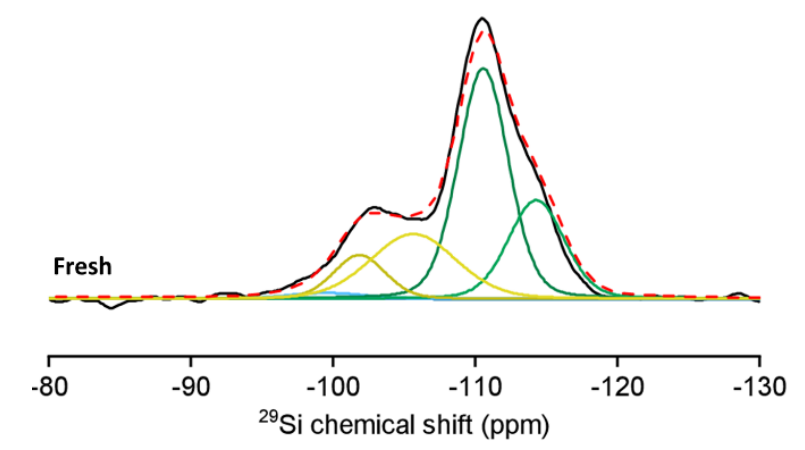

\begin{tabular}{lcc} 
& Chemical shift (ppm) & Fraction (\%) \\
\hline $\mathrm{Si}(\mathrm{OSi})_{2}(\mathrm{OH})_{2}$ & $-92,7$ & 0,0 \\
$\mathrm{Si}(\mathrm{OSi})_{3}(\mathrm{OH})$ & $-99,5$ & 1,8 \\
$\mathrm{Si}(\mathrm{OSi})_{4-n}(\mathrm{OAI})_{n} \quad(n=1,2)$ & $-101,9$ & 8,9 \\
$\mathrm{Si}(\mathrm{OSi})_{4-n}(\mathrm{OAI})_{n} \quad(n=1)$ & $-105,6$ & 21,9 \\
$\left.\mathrm{Si}_{(\mathrm{OSi}}\right)_{4}$ & $-110,6$ & 45,7 \\
$\left.\mathrm{Si}_{(\mathrm{OSi}}\right)_{4}$ & $-114,3$ & 21,8 \\
& & \\
& &
\end{tabular}

Figure 3. ${ }^{29} \mathrm{Si}$ MAS NMR spectra and their decompositions into contributions of Si from different environments of the fresh $\mathrm{H}$-Beta 10.8 catalyst (bottom), the twice reused and calcined, dealuminated $\mathrm{H}$-Beta (middle) and the realuminated H-Beta catalyst (top). The black curve represents the measured NMR spectrum and the red dashed curve represents the modeled spectrum. 

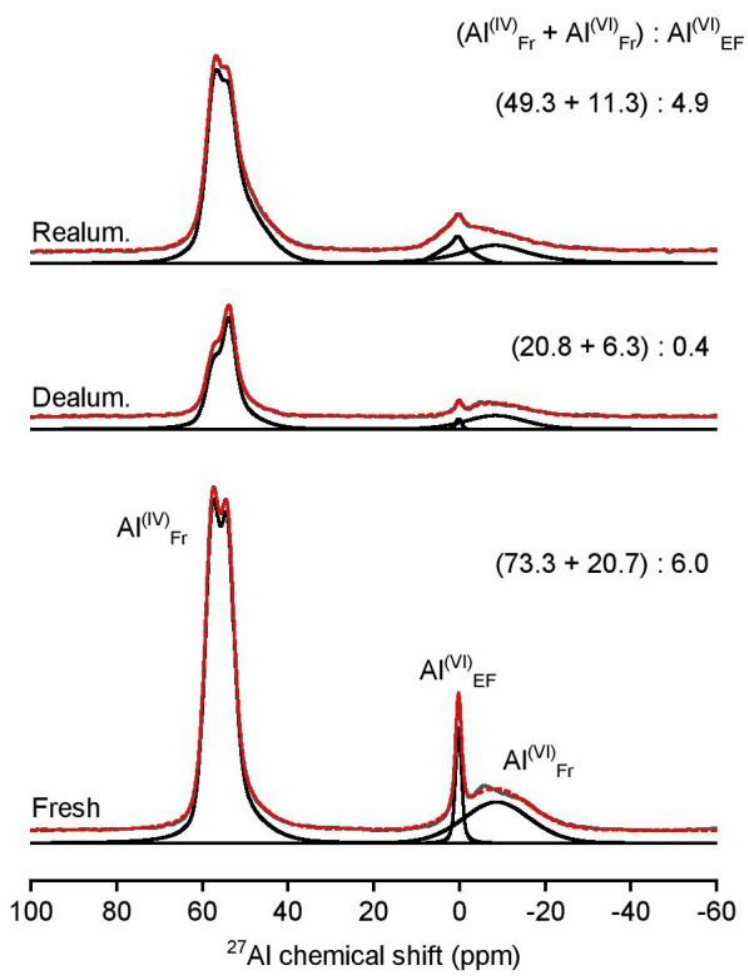

Figure 4. Comparison of the ${ }^{27} \mathrm{Al}$ MAS NMR spectra of the fresh H-Beta 10.8 (bottom), the twice reused and calcined, dealuminated $\mathrm{H}$-Beta (middle) and the realuminated $\mathrm{H}$-Beta catalyst (top). The amount of Al present as tetrahedral framework $\mathrm{Al}$ and octahedral framework (broad signal extending between 0 and $-25 \mathrm{ppm}$ ) and extra-framework (narrow signal at 0 ppm) Al for the different $\mathrm{H}$-Beta zeolites is noted above the respective ppm-regions relative to the amount of Al present in the fresh $\mathrm{H}$ Beta zeolite.

\section{Conclusion}

In conclusion, a direct synthesis route for propane-1,2,3-tricarboxylic acid (PTA) from the abundant citric acid was successfully developed via a sequential dehydration-hydrogenation process. By applying a low Si/Al H-Beta solid acid zeolite in combination with $0.5 \mathrm{~mol} \% \mathrm{Pd} / \mathrm{C}$, the dehydration of citric acid to aconitic acid was achieved at low reaction temperatures, thereby suppressing the undesired decarboxylation of aconitic acid and boosting the selectivity for PTA. Under relatively mild reaction conditions $\left(160^{\circ} \mathrm{C}, 10 \mathrm{bar} \mathrm{H}_{2}\right)$ and in water as a green solvent, a yield of $85 \%$ PTA was obtained after $20 \mathrm{~h}$. Further investigation on the role of the acid catalyst elucidated that Lewis acidity also facilitates the dehydration of citric acid in aqueous acidic media. From these findings we concluded that next to hydrothermal stability and an adequate amount and accessibility of acid sites, the combined interaction of Brønsted and Lewis acid sites in the zeolite channels accounts for the superiority of low Si/Al H-Beta zeolites for the dehydration of citric acid. Finally, recycling experiments were performed, where the gradual decay in citric acid conversion upon following reuses was attributed to loss of acid sites due to dealumination. We have shown that upon realumination a considerable amount of Al was reincorporated into the zeolite framework. This resulted in an increase of the conversion of citric acid while a high selectivity to PTA was preserved, illustrating that this realumination technique is a suitable approach to recycle the catalytic system.

\section{Author information}

\section{Corresponding Author}

E-mail: dirk.devos@kuleuven.be.

\section{ORCID}

Wouter Stuyck: 0000-0002-2887-0580. 


\section{Funding}

W.S. and J.V. are grateful to the FWO for their PhD fellowships. G. M. and D.E.D.V. acknowledge FWO for research project funding (G0781118N, G0D0518N); D.E.D.V. thanks KULeuven as well for long-term structural funding through Metusalem (METU14/04). A. K. and G. M. acknowledge the financial support from the Slovenian Research Agency (research core funding No. P1-0021 and project No. N1-0079).

\section{Conflicts of interest}

There are no conflicts to declare.

\section{Acknowledgements}

The authors also thank Jannick Vercammen for catalyst synthesis and Karel Duerinckx and prof. Dimitrios Sakellariou for assistance with ${ }^{1} \mathrm{H}$ - and ${ }^{27} \mathrm{Al}$ NMR measurements respectively.

\section{References}

1 R. Geyer, R. J. Jambeck and K. Lavender Law, Science advances, 2017, 3, e170082.

2 Ellen MacArthur Foundation, The New Plastics Economy: Rethinking the future of plastics, 2016, Retrieved from: https://www.ellenmacarthurfoundation.org/. Accessed on April 2, 2020.

3 Markets and Markets, Plastics Additives Market by Type, Plastics and by Application - Global Trends \& Forecasts to 2021, 2016, Retrieved from: https://www.marketsandmarkets.com/. Accessed on April 2, 2020.

4 M. Bocqué, C. Voirin, V. Lapinte, S. Caillol and J.-J. Robin, Journal of Polymer Science, Part A: Polymer Chemistry, 2016, 54, 11-33.

5 P. Walters, D. F. Cadogan and C. J. Howick, Plasticizers in Ullmann's Encyclopedia of Industrial Chemistry, WileyVCH Verlag, Germany, 2020, pp. 1-27.

6 European plasticisers, Plasticisers, March 2020, Retrieved from: https://www.plasticisers.org/. Accessed on April 2, 2020.

7 K. J. Groh, T. Backhaus, B. Carney-Almroth, B. Geueke, P. A. Inostroza, A. Lennquist, H. A. Leslie, M. Maffine, D. Slunge, L. Trasande, A. M. Warhurst and J. Muncke, Science of the Total Environment, 2019, 651, 3253-3268.

8 C. Bueno-Ferrer, M.C. Garrigós and A. Jiménez, Polym. Degrad. Stab., 2010, 95, 2207-2212.

9 B. Yin and M. Hakkarainen, J. Appl. Polym. Sci., 2011, 119, 2400-2407.

10 A. Greco, D. Brunetti, G. Renna, G. Mele and A. Maffezzoli, Polymer Degradation and Stability, 2010, 95, 21692174.

11 Z. Yu, J. Zhou, J. Zhang, K. Huang, F. Cao and P. Wei, J. Appl. Polym. Sci., 2014, 40938.

12 M. Matos, R. A. Cordeiro, H. Faneca, J. F. J. Coelho, A. J. D. Silvestre and A. E. Sousa, Materials, 2019, 12, 2336.

13 I. E. Sweis and B. C. Cressey, Toxicology Reports, 2018, 5, 808-812.

14 E. Snejdrova and M. Dittrich, Pharmaceutically Used Plasticizers in Recent Advances in Plasticizers, IntechOpen, 2012, pp. 45-68.

15 F. Welle, G. Wolz and R. Franz, Pharma International, 2005, 3, 17-21.

16 SCENIHR, Preliminary report on the safety of medical devices containing DEHP-plasticized PVC or other plasticizers on neonates and other groups possibly at risk, European Commission 2007.

17 Acetylation: a) S. Ting, CN101353305B, 2007. b) B.L. Song, G. Zhang, Y.Z. Wang and W.J. Yanli, CN101402571A, 2008. c) G. Kia, Z. Yang, Z. Pengwei, H. Wei, L. Xiaolin, CN102351696B, 2011. d) L. Jianzhong, Z. Yuepeng, L. Hiulai, CN102633640B, 2012. e) C. Xingjian, CN106928065A, 2017. Butyrylation: a) J.F. Day, US20060094894A1, 2004.

18 F. C. Magne, R. R. Mod, Ind. Eng. Chem., 1953, 45, 1546-1547.

19 R. J. Reid, C. Fulton, W. M. Smith Jr. C. Falls and B. H. Werner, US2802802, 1957.

20 G. E. Hilbert, Premium-quality plasticizers made from aconitic acid, a byproduct of sugarcane in Annual Reports of Department of Agriculture, United States, 1952, 62-64.

21 Wypych G., Handbook of Plasticizers, $3^{\text {rd }}$ edition, ChemTec Publishing, Toronto, 2017.

22 J. Verduyckt and D. E. De Vos, Chem. Sci., 2017, 8, 2616-2620.

23 B. M. Stadler, C. Wulf, T. Werner, S. Tin and J. G. de Vries, ACS Catal., 2019, 9, 8012-8067.

24 G. Flèche and M. Huchette, Starch, 1986, 38, 26-30. 
V. E. Tarabanko, M. Yu. Chernyak, S. V. Aralova and B. N. Kuznetsov, React. Kinet. Catal. Lett., 2002, 75, 117126.

26 B. Danon, G. Marcotullio and W. de Jong, Green Chem., 2014, 16, 39-54.

K. Bock, C. Pedersen and H. Thøgersen, Acta Chemica Scandinavica B, 1981, 35, 441-449.

R. M. Ravenelle, F. Schüßler, A. D'Amico, N. Danilina, J. A. van Bokhoven, J. A. Lercher, C. W. Jones and C. Sievers, J. Phys. Chem. C, 2010, 114, 19582-19595.

Xu, S. Huang and W. Zhang, Catal. Sci. Technol, 2019, 9, 5676-5685.

M. Carlsson, C. Habenicht, L. C. Kam, M. J. Antal Jr., N. Bian, R. J. Cunningham and M. Jones Jr., Ind. Eng. Chem. Res., 1994, 33, 1989-1996.

37 R. T. Arnold, O. C. Elmer and R. M. Dodson, J. Am. Chem. Soc., 1950, 72, 4359-4361.

38 J. Le Nôtre, S. C. M. Witte-van Dijk, J. van Haveren E. L. Scott and J. P. M. Sanders, ChemSusChem, 2014, 7, 27122720.

39 J. Rigoreau, S. Laforge, N.S. Gnep, M. Guisnet, Journal of Catalysis, 2005, 236, 45-54.

40 N. Y. Chen, J. Phys. Chem., 1976, 80, 60-64.

41 A. Corma, Current Opinion in Solid State \& Material Science, 1997, 2, 63-75.

42 T. Ennaert, J. Geboers, E. Gobechiya, C. M. Courtin, M. Kurttepeli, K. Houthoofd, C. E. A. Kirschhock, P. C. M. M. Magusin, S. Bals, P. A. Jacobs and B. F. Sels, ACS Catal., 2015, 5, 754-768.

43 L. Xiao, J. Mao, J. Zhou, X. Guo and S. Zhang, Applied Catalysis A: General, 2011, 393, 88-95.

44 D. Barthomeuf, Stud. Surf. Sci. Catal., 1997, 105, 1677-1706.

45 I. Kiricsi, C. Flego, G. Pazzuconi, W. O. Parker Jr., R. Millini, C. Perego and G. Bellussi, J. Phys. Chem., 1994, 98, 4627-4634.

46 G. H. Kuehl and H. K. C. Timken, Microporous and Mesoporous Materials, 2000, 35-36, 521-532.

47 O. Bortnovsky, Z. Sobalík, B. Wichterlová and Z. Bastl, Journal of Catalysis, 2002, 210, 171-182.

48 E. Bourgeat-Lami, P. Massiani, F. Di Renzo, P. Espiau and F. Fajula, Applied Catalysis, 1991, 72, $139-152$.

49 J. Dedecek, E. Tabor and S. Sklenak, ChemSusChem, 2019, 12, 556-576.

50 J. Brus, L. Kobera, W. Schouferger, M. Urbanová, P. Klein, P. Sazama, E. Tabor, S. Sklenak, A. V. Fishchuk and J. Dedecek, Angewandte Chemie, 2015, 54, 541-545.

51 O. Bortnovsky, Z. Sobalík and B. Wichterlová, Microporous and Mesoporous Materials, 2001, 46, 265-275.

52 J. Pérez-Pariente, J. Sanz, V. Fornés and A. Corma, Journal of Catalysis, 1990, 124, 217-223.

53 J. A. van Bokhoven, D. C. Koningsberger, P. Kunkeler, H. van Bekkum and A. P. M. Kentgens, J. Am. Chem. Soc., 2000, 122, 12842-12847.

54 S. M. Maier, A. Jentys and J. A. Lercher, J. Phys. Chem. C, 2011, 115, 8005-8013.

55 A. Vjunov, J. L. Fulton, T. Huthwelker, S. Pin, D. Mei, G. K. Schenter, N. Govind, D. M. Camaioni, J. Z. Hu and J. A. Lercher, J. Am. Chem. Soc., 2014, 136, 8296-8306.

56 Z. Zhao, S. Xu, M. Y. Hu, X. Bao, C. H. F. Peden and J. Hu, J. Phys. Chem. C, 2015, 119, 1410-1417.

57 A. Omegna, M. Vasic, J. A. van Bokhoven, G. Pirngruber and R. Prins, J. Phys. Chem. Chem. Phys., 2004, 6, 447452.

58 D. M. Roberge, H. Hausmann and W. F. Hölderich, J. Phys. Chem. Chem. Phys., 2002, 4, 3128-3135. 